\title{
La esencia de la Técnica (Das Ge-stell) como un habitar (Whonen)
}

\author{
Ulises Salomón Amaya ${ }^{1}$ \\ Recibido en abril de 2015, aceptado en mayo de 2015. \\ "Como la naturaleza abandona a los seres \\ Al riesgo de su oscuro deseo..."
}

Rilke

\begin{abstract}
Resumen
El presente ensayo se propone una aproximación a la reflexión heideggeriana sobre la técnica. En un primer momento se realizará una aproximación a los tres modos cotidianos que constituyen la estructura existencial de la cotidianidad a fin de establecer una aproximación al vínculo onto-existencial que posee con la reflexión heideggeriana sobre la técnica. Para, en un segundo momento, señalar sus relaciones con otros términos heideggerianos fundamentales en el despliegue del pensamiento del que se ha llamado el segundo Heidegger.
\end{abstract}

\section{Palabras claves:}

Cotidianidad, estar-en-el-mundo, Ge-stell, desocultar-provocante,constante, habitar.

\begin{abstract}
:
The current essay proposes an approximation to the heideggerian reflection about technique. In a first moment, an approximation to the three constitutive everyday modes of the existential structure of everydayness will be made, in order to establish the Onto-existential bond with the heideggerian reflection about technique. This, in a second moment, will seek to point its relations with other fundamental heideggerian terms in the deployment of thinking known as the second Heidegger.
\end{abstract}

\section{Keywords:}

Everydayness, being-in-the-world, Ge-stell, provocative-unhiding, constant dwelling.

1. Doctorando por la Pontificia Universidad Católica de Valparaíso, Chile. Beneficiario Beca Postgrado PUCV 2015. E-mail: ulises.amaya.p@mail.pucv.cl 


\section{Introducción}

Interrogar por la técnica tiene un profundo valor a la hora de acercarnos a la filosofía heideggeriana debido al papel fundamental que dicha temática ocupa en el despliegue de su pensamiento del autor. Especialmente en aquella etapa que los especialistas han llamado el segundo Heidegger, etapa en la cual, según nuestro autor, "el pensamiento se vuelve más resueltamente al ser en cuanto ser"2. La técnica implica, para Heidegger, cierta ambigüedad; por un lado revela el destino que emerge del ser mismo, y que podría provocar una relación más originaria entre el ser y el hombre; pero esto, que podría ser una vuelta al ser, esconde también en sí mismo la posibilidad de extravío del carácter más específico del hombre. La esencia ${ }^{3}$ de la técnica que Heidegger llamara Ge-stell implica de esta manera un peligro, pero no cualquier tipo de peligro, sino un peligro que en sí mismo contiene ya la salvación. Dicho en términos heideggerianos, el Ereignis. "El Ge-stell, por así decirlo, es el negativo fotográfico del Ereignis"4.

La reflexión heideggeriana por la técnica es de 1953, es decir, después de la vuelta (Keh-re), en este sentido, es importante señalar que aunque el pensamiento heideggeriano ha sido dividido en dos momentos ${ }^{5}$; la analítica existencial y la vuelta o viraje (Die Kehre), esto no significa que exista una discontinuidad en el despliegue del pensamiento de nuestro autor ${ }^{6}$. El sustantivo en alemán, die

2. Heidegger, Martin, Seminario Le Thor 1969, Traducción de Diego Tatián, Alción editora, Córdoba, 1995. Visto en, http://www.heideggeriana.com.ar/textos/le_thor.htm

3. Es importante señalar lo que Heidegger comprende por esencia. Esencia en el pensamiento heidegge-riano no hace referencia a lo general, es decir, aquello que podríamos decir es común de una clase de objetos, para Heidegger esta concepción tradicional esencial es realmente inesencial, por lo que sería una suerte de esencia-inesencial, para Heidegger, nos dicen Jorge Acevedo, la esencia-esencial se caracteriza por los siguientes rasgos: 1)Está más allá de lo meramente constatable, 2)Domina el ambito de lo que se halla ante los ojos, 3)Desde la esencia se explica el ámbito de lo meramente constatable, 4)La esencia esencial no es ajena al ser humano, existe una relación entre ambos, 5)Cuando se alcanza la esencia de algo se es capaz de ver su relación con el Ser, es decir, se es capaz de verlo como mani-festación del Ser, 6)Ya que el Ser es histórico la esencia también lo es, 7)El que la esencia sea histórica no significa que no perdure, sino que perdura reuniendo y garantizando el ser de lo que reúne, y 8)El lenguaje es aquello que nos permite acceder a la esencia, esto porque el lenguaje al igual que el Ser y la esencia también es histórico.

4. Ibidem.

5. Modesto Berciano afirma que el concepto clave del pensamiento heideggeriano es el Ereignis y es desde éste que debe comprenderse todo su desarrollo filosófico. El mismo Heidegger, nos dice Berciano, reconocería que desde 1936 el Ereignis habría sido el concepto fundamental de su planteamiento. Véase Berciano, Modesot, "El evento (Ereignis) como concepto fundamental de la filosofía en Hei-degger", en, Acercamiento a la obra de Martin Heidegger. Sociedad castellanaleonesa de Filosofía, Salamanca 1991, pp.91-118.

6. Basta recordar que en 1962 el mismo Martin Heidegger comenta en el prólogo a la obra del sacerdote jesuita, William Richardson, Trought Phenomenology to Thought de 1963, que la maduración de un complejo temático (Sachverhalt) a través de un largo tiempo fue lo que produjo la Kehere, además, en el Protokoll zu einem Seminar über den Vortrag "Zeit und Sein" del 1962, Heidegger afirma que aquello que constituye la estructura esencial del Ereignis han sido elaborados entre 1935 y 1936. F.W. von Herrmann en 1991 al interpretar la Kehere como la estructura misma del acaecer inicia una nueva línea de comprensión del pensamiento heideggeriano, así, abre una nueva lectura de la obra heideggeriana como un todo unitario. Cfr. Basso Monteverde, Mercedes 
Kehre, que se ha solido traducir como vuelta o viraje no solo significa esto, sino también, la acción de dar vuelta a la página, de un anverso a un reverso, siendo ambas caras la misma página ${ }^{7}$, con lo que no habría una discontinuidad, tal como se mencionó anteriormente, sino un cambio de posicionamiento, después de la Kehre, el filósofo de la selva negra habita lo velado, el silencio (Erschweigung), el abismo (Abgrund), es decir, el Ser. Además, es fundamental señalar que esta división, ampliamente aceptada, no muestra de manera adecuada, nos parece, la radicalización que su pensamiento fue adquiriendo hasta advenir en el concepto de Ereignis, concepto que apareció por primera vez en 1919, y que no fue sino hasta Beiträge zur Philosophie (Vom Ereignis) ${ }^{8}$ que inicia un desplazamiento hasta llegar a ocupar el centro del pensar heideggeriano llegando en su etapa tardía inclusive, en cierta forma, a desvanecer al Ser $(\text { Sein })^{9}$. "Desde la carta sobre el humanismo, continuo diciendo Sein, ser, pero pienso Ereignis, acontecimiento apropiador" ${ }^{10}$. Dicho lo anterior, "La pregunta por la técnica" (Die Frage nach der Technik, 1953) que es posterior a "La vuela”

Leticia, Génesis y constitución del Ereignis, un estudio de la continuidad de la obra de Martin Heidegger, [1919-1939] a través del problema de la diferencia ontológica, Tesis para optar al grado de Doctora en Filosofía, UBA, Argentina, 2013, pp.5-6

7. Dicha explicación del término Kehre fue expuesta -en una entrevista realizada como parte de nuestra investigación doctoral- por el Profesor y Doctor Breno Onetto Muñoz de la Universidad Austral de Chile quien ha realizado una de las dos traducciones de los Beiträge zur Philosophie (vom Ereignis) de Martin Heidegger, Contribuciones a la Filosofía (Del acontecimiento), traducción realizada como proyecto de investigación de su postdoctorado presentado en 1998 y que fuera aprobado en marzo 29 de 1999, y que además contara con la colaboración de Jorge Eduardo Rivera, traductor de Ser y tiempo. Al final de la introducción de dicha traducción nos dice Onetto, “... el ser acontece en todas las épocas de la historia acontecedora del hombre, la mayoría de las veces en el modo del 'abandono del ser'; mas como efectivo acontecimiento se da este Ser recién en aquello que Heidegger ha llamado el "giro", la Kehre. Un término que permite distinguir, al menos, tres sentidos: a) como Umkerhr [ung] o Rückkehr, o sea, en el sentido de un volverse hacia atrás o regresar a la experiencia primera del ser de los pensadores griegos anteriores a Platón, o sea, el pensamiento que Heidegger llama el "primer inicio", el cual no ha de ser restaurado de ninguna manera, ni mucho menos imitado. pero si se le ha de contraponer necesariamente con el de Platón. b) como el estar vuelto el uno hacia el otro de Ser y Da-sein. Lo que significa que no hay Ser sin Da-sein, sin el ser propio del hombre, ni Da-sein sin el Ser. Pues solamente en la experiencia de la verdad del Ser viene el hombre a ser [su] sí mismo, y sólo si se experimenta ésta en el ahí originario, deviene el Ser en acontecimiento. De allí que el Ereignis sea determinado así como 'Ereignis der Dagründung', como acontecimiento de la fundación del ahí, a saber, de dos formas: como 'a-propiamiento del Da-sein a través del Ser', y como 'fundación de la verdad en el Da-sein'. Luego, el Ereignis del Ser es esencialmente Kehre, un giro intercambiable, juego reciproco entre Ser y Da-sein. Llamado en los 'Beiträge', también 'das in sich gegenschwingende Ereignis', el acontecimiento que reverbera en sí [mismo]. c) y cuando ese estar vuelto el uno hacia el otro de Ser y Da-sein -que ha sido preparado por el retorno a la experiencia del ser preplatónica- entra en vigencia y se logra así ‘la gran inversión...' en la que los entes vienen a ser fundados no desde el hombre, sino que el ser del hombre es fundado a partir del Ser. La otra traducción es de Dina Picotti, Aportaciones a la filosofía acerca del evento, en Editorial Biblos, Argentina, 2003.

8. Beiträge zur Philosophie (Vom Ereignis) es considerada la segunda obra de importancia de Heidegger (1936'1938) publicada postumamente en 1989.

9. Cfr. Del Barco, Oscar, “Sobre el concepto de Dios en Heidegger”, en, Exceso y Donación. La Búsqueda del Dios sin Dios, Biblioteca Internacional Martin Heidegger, Buenos Aires, 2003, pp. 97-112, visto en: http://www.heideggeriana.com.ar/comentarios/del_barco.htm

10. Beaufret, Jean, Dialogue avec Heidegger. IV. Le chemin de Heidegger, Les Éditión de Minuit, París, 1985, p.126 
(die Kehre, 1949), no es ajena a lo planteado en la analítica existencial en Sein und Zeit (1927).

En lo que sigue, pretendemos establecer la relación que la pregunta por la técnica guarda con la cotidianidad (Alltäglichkeit) del Dasein, y por lo tanto con su estar-en-el-mundo (In-der-Welt-Sein) ${ }^{11}$ para, en un segundo momento, esbozar los rasgos fundamentales de la Ge-stell y aquellas relaciones esenciales que ésta posee con otros términos heideggerianos.

\section{La cotidianidad (Alltäglichkeit) del Dasein y la técnica (Technik).} Heidegger comprende la cotidianidad (Alltäglichkeit) no desde las prácticas efectivas que implica el formar parte de una sociedad, sino, desde la situación de impersonalidad, normalidad e indiferencia en la cual habita, por la caída (Verfallen) de su aperturidad (Erschlossenheit), del Dasein. El extravío entre los entes y al dominio anónimo de los otros es lo que constituye la cotidianidad (Alltäglichkeit) del estar-en-el-mundo (In-der-Welt-sein).

“Por lo pronto, el Dasein ha desertado siempre de sí mismo en cuanto poder-ser-sí-mismo propio, y ha caído en el "mundo". El estado de caída en el "mundo" designa el absorberse en la conveniencia regida por la habladuría, la curiosidad y la ambigüedad"12.

Habladuría, curiosidad, ambigüedad es lo que constituye el ser-cadente del Dasein y por lo tanto, su ser-en-el-mundo (In-der-Welt-sein), por lo que, son el ser-si-mismo de la forma cotidiana de su existencia. La habladuría (Gerede), es una forma del discurso (Rede) y al igual que el lenguaje también es una forma determinada de aperturidad (Erschlossenheit). En la habladuría (Gerede) el Dasein comprende e interpreta su mundo desde la impersonalidad e indefinibilidad de la publicidad del uno (Das man). El lenguaje es aquello que abre el y al mundo, al nombrar las cosas éstas comparecen y el Dasein trata de aprehenderlas como de suyo, así, es comprensión-aprehensión, y además, es diálogo, por lo que el lenguaje conlleva la escucha, y esta escucha es también aprehensora, lo que significa que en el diálogo el Dasein es, busca escapar de

\footnotetext{
11. Jorge Eduardo Rivera sostiene que se ha solido traducir In-der-Welt-sein como ser-en-el-mundo, sin embargo, esta traducción no mostraría el acto mismo de ser sino que haría referencia a algo quiditativo, por ello, él prefiere la traducción de estar-en-el-mundo porque esta forma estaría más en conso-nancia con el carácter ejecutivo del Dasein puesto que remitiría a su carácter existencialontológico, además, y esto me parece sumamente relevante, para Rivera estar-en-el-mundo no expresaría un estar colocado, sino más bien, una acción progresiva que bien podría expresarse en gerundio, estar-siendo-en-el-mundo, lo que implicaría, para Rivera, la idea de Habitar, idea que será fundamental en el Heidegger posterior a los Beiträge zur Philosophie.

12. Das Dasein ist von ihm selbst als eigent-lichem Sebstseinkönen zunächst immer schon abgefallen un and die »Welt« verfallen. Die Verfallenheit an die »Welt« mein das Aufgehen im Miteinandersein, sofern dieses durch Gerede, Neugier und Zweideutigkeit geführt wird. Heidegger, Martin, Sein und Zeit, Max Niemeyer Verlag GmbH, Tübingen 2001, § 38, p. 175. En adelante cuando se cite Sein und Zeit se citará de la siguiente manera SuZ.
} 
superficialidades y aprehender lo que el otro es de suyo.

La habladuría (Gerede) también es una manifestación de ese lenguaje, pero un lenguaje cadente que al formar parte del ser-si-mismo de la cotidianidad (Alltäglichkeit) escapa de ir a las cosas como de suyo y más bien se queda en la medianía que la cotidianidad (Alltäglichkeit) es. Esta manifestación cadente del lenguaje no pretende una comprensión aprehensora de los entes, no pretende ir a lo que éstos "son", sino quedarse en lo dicho, en lo "se dice", el diálogo así se diluye en ese carácter impersonal. Diálogo implica una pretensión clara comunicativa bidireccional, se busca no sólo la comunicación, sino también la escucha. En la habladuría (Gerede) no importa si quien escucha "realmente escucha" o comprende aquello que ha sido dicho, es irrelevante el otro que dialoga, por lo que las palabras son palabras desarraigadas. Al quedarse en la medianía de la cotidianidad la habladuría se torna una verdad incuestionable, el "se dice" es fuente de verdad, nada escapa del conocimiento ni de la vivencia del "se dice". Heidegger afirma en Sein und Zeit:

"La habladuría es la posibilidad de comprenderlo todo sin apropiarse previamente de la cosa. La habladuría protege de antemano del peligro de fracasar en semejante apropiación. La habladuría que está al alcance de cualquiera, no sólo exime de la tarea de una comprensión auténtica, sino que desarrolla una comprensibilidad indiferente, a la que ya nada está cerrado" ${ }^{13}$.

Otra de las estructuras existenciales del estar-en-el-mundo (In-der-Weltsein), y que por lo tanto, es un carácter de la cotidianidad (Alltäglichkeit), es la curiosidad (Neugier), ésta es la afición por la novedad, por ello, la vista adquiere un papel fundamental en esta estructura existencial. En la curiosidad (Neugier) el Dasein queda extraviado y avasallado por la novedad de las cosas que comparecen ante él, y denota, además, una tendencia a una particular forma de encuentro perceptivo con el mundo. El Dasein queda atrapado en ese afán de lo novedoso, lo que no implica, al igual que en la habladuría (Gerede), que haya un interés por la verdad, "La avidez de novedades, es un indisciplinado interés por todo. Es una especie de saber, pero no con el objeto de saber, sino «simplemente para tener sabido»"14. El afán por lo nuevo hace que el Dasein tenga una tendencia desmesurada hacia todo lo novedoso, pero, sin aprehender la verdad que hay en ello, sino simplemente por el carácter de novedad que posee. En este sentido en Sein und Zeit se nos dice:

13. Das Gerede ist die Möglichkeit, alles su verstehen ohne vorgängige Zueignung der Sache. Das Gerede behütet schon vor der Gefahr, bei einer solchen Zueignung zu scheitern. Das Gerede, das jeder aufraffen kann, entbindet nicht nur von der Aufgabe echten Verstehens, sondern bildet eine indifferent Verständlichkeit aus, der nichts mehr verschlossen ist. Heidegger, Martin, SuZ, § 35, p. 169.

14. Cohn, Priscilla, Heidegger, su filosofía a través de la nada, Ediciones Guadarrama, Madrid, 1975, p. 49. 
"Los dos momentos constitutivos de la curiosidad, la incapacidad de quedarse en el mundo circundante y la distracción hacia nuevas posibilidades, fundan el tercer carácter esencial de este fenómeno, que nosotros denominamos la carencia de morada [Aunfenthalts-losigkeit]. La curiosidad de halla en todas partes y en ninguna. Esta modalidad del estar-en-el-mundo revela un nuevo modo de ser del Dasein cotidiano, en el que éste se desarraiga constantemente". ${ }^{15}$

Este análisis heideggeriano, después de die Kehre se agudizará más cuando Heidegger reflexione sobre la técnica, porque dicha reflexión no partirá más del Dasein, sino del Ser (Sein) mismo, sin embargo, la analítica existencial continuará estando presente, aunque nuestro autor habite posicionado de cara a los supuestos que subyacen a Sein und Zeit, y no ya desde ellos.

"Ser, hoy, es ser reemplazable. La idea misma de "reparación" ha llegado a ser una idea "antieconómica". Por todo ente de consumo es esencial ser consumido ya, y llama así a su reemplazo. Tenemos aquí uno de los rostros de la desaparición de lo tradicional, de lo que se transmite de generación en generación. Incluso en el fenómeno de la moda lo esencial no es ya el aspecto (en cuanto tal, la moda se ha convertido en algo tan anacrónico como el remiendo), sino la reemplazabilidad de los modelos, de temporada en temporada. La vestimenta no se cambia más cuando y porque se ha hecho defectuosa, sino porque tiene el carácter esencial de ser "el vestido del momento esperando el siguiente"16.

Estas dos estructuras existenciales, la habladuría (Gerede) y la curiosidad (Neugier) ocupan al Dasein y hacen que éste pierda la perspectiva del carácter de verdad (Warheit) de su conocimiento, es decir, el Dasein ya no sabe si eso que cree saber es la verdad (Warheit) del mundo (Welt) y de los entes. Esto nos conduce a la última estructura existencial de la cotidianidad (Alltäglichkeit), a saber, la ambigüedad (Zweigdeutigkeit), al no haber nada que escape a la habladuría (Gerede) y nada que no haya sido visto por la curiosidad (Neugier) y al ser esta cotidianidad (Alltäglichkeit) que el Dasein habita (Whonen), éste ya no puede saber si el conocimiento que tiene es verdadero, y por lo tanto, si ha habido o no una comprensión auténtica. La ambigüedad (Zweigdeutigkeit) no sólo afecta la relación del Dasein con su mundo, sino también con la comunidad y consigo mismo ${ }^{17}$.

15. Die beiden für die Neugier Konstitutiven momente des Unverweilens in der besorgten Umwelt und der Zerstreuung in neue Möglichkeiten fundieren den dritten Wesenscharakter dieses Phänomens, den wir die Aunfenthalslosigkeit nennen. Die Neugier ist überall und nirgends. Dieser Modus des In-der-Welt-seins enthüllt eine neue Seinsart des Alltäglichen Daseins, in der es sich ständing entwurzelt. Heidegger, Martin, SuZ, § 36, p. 172.

16. Heidegger, Martin, Seminario de Lethor 1969, op.cit. visto en: http://www. heideggeriana.com. ar/comentarios/del_barco.htm

17. Cfr. Heidegger Martin, Ser y tiempo, Traducción, prólogo y notas, Jorge Eduardo Rivera, Trotta, 
La cotidianidad (Alltäglichkeit) es entonces ese trato en el mundo, con el ente intramundano y el ente en su totalidad, el cual implica una multiplicidad de formas de ocuparse, siendo ésta la forma en la que el Dasein es un estar-enel-mundo (In-der-Welt-sein), es decir, habita (Whonen) el mundo. Estas formas de ocuparse están caracterizadas por algo que se encuentra estrechamente relacionado con la técnica moderna, el manipular y el utilizar. Para Heidegger este manipular y utilizar es la manera más radical que el Dasein, como sercadente, tiene de habérselas con las $\operatorname{cosas}^{18}$, éstas, al comparecer como aquello que puede ser manipulado y utilizado recibe el nombre de útil (Nüztlich). Así, el mundo comparece en esa multiplicidad de formas de ocuparse del útil (Nüztlich) y en el tejido de respectividades que este útil (Nüztlich) establece. Para desvelar cómo la intencionalidad técnica constituye al útil (Nüztlich), Heidegger utiliza el concepto de lo «a la mano» (Zuhandenheit), de esta manera, el carácter técnico de un ente está fundado en la intencionalidad con que lo experienciamos, de ahí la pertinencia de haber iniciado este ensayo refiriéndonos a la manera en que el Dasein habita el mundo.

Queda clara la pertinencia de haber iniciado nuestro recorrido por la estructura existencial cotidiana del Dasein, ya que ésta es fundamental para comprender toda la reflexión heideggeriana en torno a la técnica. La técnica no es sólo una figura del ser, sino también una forma de experienciar del Dasein, de ahí la importancia de comprender el estar-en-el-mundo (In-der-Welt-sein) y, por lo tanto, el habitar como un ser-cadente, porque es desde aquí que el Dasein comprende la experiencia de la técnica. La técnica, más bien la esencia de ésta, es la que determina a ese Das man que dicta al Dasein el carácter de verdad de su habitar (Whonen), he ahí el por qué Heidegger llama insistentemente a comprender la técnica a partir de su esencia, es decir, aquello a lo que él llama Ge-stell.

\section{De la Ge-stell y sus relaciones decisivas}

La reflexión sobre la técnica no es una reflexión periférica en el pensamiento heideggeriano, y no solo eso, sino también ésta está relacionada con preocupaciones fundamentales de su filosofía: el ser (Sein), la verdad (der Warheit), el pensar (das Denken), el otro pensar (das Andere Denken), el habitar (Wohnen), el desasimiento (Gelassenheit) y otras preocupaciones que difícilmente harán de Heidegger un continuador de la metafísica occidental, ni tampoco un místico o como se podría pensar, alguien que occidentaliza la filosofía oriental.

Si queremos comprender la manera cómo acontecen esos lugares comunes entre la filosofía del pensador de la selva negra y la filosofía oriental que llamó tanto la atención a grandes pensadores de Oriente -entre quienes podemos mencionar al Nishida Kitaro, quien fue uno de los primeros introductores de 
la fenomenología a Japón y estudió con Husserl y Heidegger, Keiji Nishitani, discípulo de Nishida, al barón kaki (el traductor de Sein und Zeit al japonés), Tomio Tezuka, Tsuhimura, H. Hisamatsu, y Daisetz Teitaro Suzuki, todos estos a pensadores asistieron a Freiburg y estudiaron con Heidegger- no debe de perderse de vista el interés heideggeriano, después de Sein und Zeit, por el otro pensar (das Andere Denken). Otro elemento fundamental es la lectura que hizo Heidegger de autores como: Meister Eckhart, Jakob Böhme, el pseudo Dionisio, Angelus Silesius, entre otros, y su interés fundamental por la experiencia originaria presocrática - prestando especial atención al fragmento 50 de Heráclito- y es aquí, nos parece, en la lectura de estas fuentes donde podemos encontrar el origen de esos lugares comunes con la filosofía oriental. Dicho lo anterior, Heidegger realiza un recorrido bastante simple del desarrollo de la técnica; sin embargo, esto no es relevante en la reflexión heideggeriana, lo fundamental es la reflexión trascendental que Heidegger realiza de la técnica desde el ser, cabe recordar que die Frage nach der Technik es del año 1949 y los Beiträge es de los años 30, siendo esta obra la que marca ese desplazamiento a un estar situado en ese límite diáfano que es el ser (Sein). Heidegger piensa ya no desde el existente Dasein, sino desde el Ser (Sein) mismo - siendo esto lo que constituye el núcleo de la Kehre-, este es un elemento fundamental que no debe perderse de vista. Este estar situado desde el ser (Sein) expuesto en los Beiträge, valga la pena señalar, se irá radicalizando conforme el Ereignis vaya cobrando cada vez más relevancia. Por lo tanto, cuando Heidegger se pregunta por la técnica ese preguntar es un preguntar por la esencia de ella, esencia que dista de ser algo técnico.

"La técnica no es igual que la esencia de la técnica. Si nosotros buscásemos la esencia del árbol, tendríamos que elegir aquello que domina a través de todo árbol en cuanto árbol, sin ser ello mismo un árbol, que se pudiera encontrar entre los restantes árboles"19. En el Heidegger tardío, la esencia de la técnica Ge-stell, está profundamente vinculada al Ereignis ${ }^{20}$, tanto así, que el mismo Heidegger diría que la Ge-stell es el negativo fotográfico del Ereignis, o como dice Felix Duque, “[...] el Ge-stell, el máximo «peligro» y a la vez un «destello» del Ereignis" ${ }^{21}$.

\footnotetext{
19. Die Technik ist nicht das gleiche wie das Wesen der Technik. Wenn wir das wesen des Baume suchen, müssen wir gewahr werden dass jenes, was jeden Baum als Baum durchwaltet, nicht selber ein Baum ist, der sich zwischen den übrigen Bäumen antreffen lässt. Heidegger, Martin, “Die Frage nach der Technik", en, Vorträge und Aufsätze, Gesaumtausgabe Band 7, Vittorio Klosterman, Frankfurt am Main, 2000, p. 5. Heidegger, Martin, “La pregunta por la técnica”, en, Filosofía ciencia y técnica, Prólogos de Franciso Soler y Jorge Acevedo, Editorial Universitaria, Santiago de Chile, 1997.

20. “Como es sabido el Ereignis es el gran tema del último Heidegger [...] cuando aquí hablemos del "último" Heidegger nos referiremos al sentido de esa evolución, que culmina en la afirmación de que el ser es algo ulterior al Ereignis. Con este término, normalmente traducido como "acontecimiento", "acontecimiento apropiatorio" o “evento", Heidegger se refiere a algo que está más allá del ser entendido como presencia. El Ereignis expresaría la máxima radicalización de la filosofía de Heidegger”. González, Antonio, “Ereignis y actualidad”, en, D. Gracia (ed.), Desde Zubiri, Ed. Comares, Granada, 2004, pp. 102-193.
}

21. Duque, Felix, "En los confines de la metafísica”, en, Anales del Seminario de Historia de la 
El Dasein es un estar-en-el-mundo (In-der-Welt-sein), pero, ¿cómo es ese mundo que habita el Dasein?, ese mundo experienciado por él desde su intencionalidad pragmática comparece como un mundo marcado por el dominio de la técnica moderna.

"El tránsito de los entes, tal como se nos muestran ahora -entes caracterizados por la funcionalización, la perfección, la automatización, la burocratización, la información, y rasgos congruentes con esos sellos-, el tránsito, digo, desde los entes así entendidos hacia el ser puede denominarse, "paso desde la tecnología (Technologie) hacia la esencia de la técnica moderna (das Wesen der modernen Technik)" 22.

La tecnología no es la técnica, es la primera cosa que nos dirá Heidegger, es el ente dominado por la esencia de la última, pero, en ese caso, ¿qué es eso que domina lo tecnológico? Para responder esta pregunta es necesario dar un paso desde ese ente tecnificado y la metafísica que subyace en él, a esa figura del ser que Heidegger llama Ge-stell, la esencia de la técnica ${ }^{23}$, por lo que la técnica es así aquello que «hay que pensar hoy», y además, ésta marca de forma definitiva el paso del pensamiento heideggeriano al «Otro pensar» (Das andere Denken $)^{24}$.

Es importante que no perdamos de vista lo que se ha venido señalando, cuando se habla de la esencia de la técnica no se está hablando de algo técnico. Heidegger nos dice en "Die Frage nach der Technik", "Así también, la esencia de la técnica no es, en absoluto, algo técnico" ${ }^{25}$, aunque, nos dice también, la concepción común de la técnica ha considerado que ésta es un hacer del hombre. La Gestell entonces, es una figura del ser (Sein) y se vincula con elementos esenciales como el des-ocultar provocante (herausforderndes Entbergen), el ente como lo constante (Be-stand), el ser como la unicuadridad (das Geviert), y el brotar del ser como acontecimiento-apropiador (Ereignis) ${ }^{26}$.

Antes de aproximarnos a la Ge-stell y esos vínculos esenciales que tiene con otros elementos fundamentales del pensamiento heideggeriano es pertinente señalar que el término técnica proviene del griego téxvn y para los griegos ésta no se refiere solamente a la fabricación instrumen-tal de útiles, sino que engloba a todas las artes en general y acentúa su carácter creativo, la téxvn es un "saber", y en la medida que es un saber es દ́mı

Filosofía, número 13, 19-38, Servicios de publicaciones UCM, Madrid, 1996, p. 26.

22. Acevedo Guerra, Jorge, "Meditación acerca de nuestra época: una era técnica", en, Revista Observaciones filosóficas, número 3, Chile, 2006, p. 8

23. Cfr., Heidegger, Martin, "Seminario Le Thor 1969", op.cit.

24.Cfr. Borges Duarte, Irene, "La tesis heideggeriana acerca de la técnica", en, Anales del Seminario de Historia de la Filosofía, número 10, 121-156, Editorial Complutense, Madrid, 1993, p.121.

25. So ist denn auch das Wesen der Technik ganz und gar nichts Technishes. Heidegger, Martin, "Die Frage nach der Technik", Op. cit. p. 5.

26. Cfr., Acevedo Guerra, Jorge, Op. cit. p. 9. 
forma parte de la moınoıৎ se revela como una forma del desocultar, es decir que la téxvn es también traer a presencia algo que estaba oculto, es una forma de desvelación, y por lo tanto, una forma de verdad. En cuanto desocultar, la téxvn

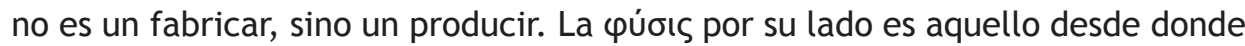
las cosas brotan, y es también un traer a presencia algo que estaba oculto,

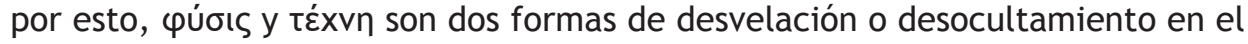
mundo griego, y es este desocultar lo determinante en ellas.

Dicho esto, se entiende que Heidegger caracterice la técnica como una forma

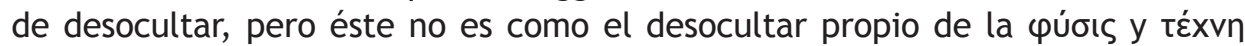
griegas, entonces ¿en qué se diferencia este desocultar propio de la técnica? La respuesta a esta pregunta será algo que aparecerá más adelante. Al inicio de "Die Frage nach der Technik" Heidegger se pregunta por la esencia de la técnica, es decir, por aquello que hay de común a todo aquello técnico, y eso que tiene de común, no puede ser algo a su vez también técnico. La esencia de la técnica, para Heidegger, sería la búsqueda de aquello que en ésta está siendo y perdurando, de lo que en ella se deja ser, y a esto es a lo que responde la palabra Ge-stell ${ }^{27}$. Lo determinante en esto que está siendo y perdurando en la técnica es la manifestación de la verdad, su desocultamiento. La técnica es entendida en una doble dimensión, como procedimientos para la realización de algo, y como los instrumentos concebidos y necesarios para la ejecución de ese algo, por eso se le ha solido comprender como una prolongación de la mano, lo cual permite tener en la mano, lo «a la mano», "[...] la técnica es la característica fundamental del homo faber, que así se afirma (técnicamente)"28.

"A lo que la técnica es pertenece el elaborar y utilizar instrumentos, aparatos y máquinas, pertenece lo elaborado y utilizado mismo, pertenecen las necesidades y fines a los que pertenecen las necesidades y fines a los que sirven. El total de estos dispositivos es la técnica. Ella misma es un dispositivo; dicho en latín: un instrumentum"29.

Por esta razón, nos dice Heidegger, existe una definición usual de la técnica que la piensa cual si fuese sólo un medio y un hacer del hombre, por ello, a esta forma de comprensión puede llamársele, la determinación instrumental y antropológica de la técnica ${ }^{30}$. Esta comprensión, que aunque no es incorrecta no es la comprensión esencial, es la que lleva al hombre a la creencia de que todo está a la mano, disponible para ser utilizado, porque la realidad es un producto,

27. Cfr., Borges Duarte, Irene, op.cit. p. 124.

28. Ibid. p. 125.

29. Zu dem, was die Technik ist, gehört das Verfertigen und Benützen von Zeug, Gerät und Maschinen, gehört dieses Verfertige und Benützte selbst, gehören die Bedürfnisse und Zwecke, denen sie dienen. Das Ganze dieser Einrichtungen ist die Technik. Sie selber ist eine Einrichtung, lateinisch gasagt: ein instrumentum. Heidegger, Martin, "Die Frage nach der Technik”, Op.cit., p.8. 30. Ibidem. 
una maquinación que conduce al hombre a sentirse incluso dueño del $\operatorname{ser}^{31}$. Como ya se ha dicho anteriormente, la esencia de aquello que sea la técnica no es algo técnico, la esencia de la técnica moderna, nos dirá el autor en "Die Frage nach der Technik", es Ge-stell y ésta es parte de la historia-destino del ser. La utilización de esta palabra para designar la esencia de la técnica ha sido un problema complejo en el estudio del pensamiento heideggeriano, no sólo por la dificultad de encontrar una traducción que dé cuenta a cabalidad de aquello que Heidegger desea señalar con este término, sino también, porque muchos de sus críticos lo consideran algo completamente irrelevante.

En este sentido, Walter Biemel nos señala que usualmente al utilizar este término en la lengua vulgar alemana, Ge-stell, nos estamos refiriendo a algo cosico, ya que esto, lo cosico, es mensurable, de ahí que dicha comprensión de Ge-stell no sea un problema y más bien nos haga sentir certidumbre en nuestra relación con aquello mensurable, sin embargo, nos señala el mismo autor, este no es el camino emprendido por la reflexión heideggeriana, nuestro autor no se mueve en términos de mensurabilidad o certidumbre. Para Heidegger, la pregunta por la técnica nos conduce a la misma aperturidad (Erschlossenheit) del ser, por lo tanto, se trata del no-ocultamiento, o más bien, desvelamiento del ser. La reflexión a partir de esta palabra alemana ${ }^{32}$ no se mueve en terrenos de lo

31. Cfr., Duque, Felix, op.cit. p. 25.

32. En este sentido es importante señalar que dentro del análisis filosófico es de suma importancia la lectura de un autor en su lengua original, esto por una sencilla razón, cada lengua es una determinada forma de comprender y habérselas con el mundo, es más, el mundo está construido a partir del lenguaje. En esta Línea, la Dra. Gloria Hinostroza de la Universidad Católica de Temuco, Chile, en su conferencia, "la construcción del mundo a través del lenguaje y la literatura" nos dice, "Al lenguaje siempre se lo entendió como instrumento que lleva contenidos, que transmite, que comunica, que expresa. Pero, no se planteó que además es acción, que genera situaciones, que transforma realidades. En otras palabras, el lenguaje genera el mundo en el que vivimos, nos pone obstáculos o nos libera de ellos: somos como somos en función de cómo nos comunicamos, de las cosas que decimos, de cómo escuchamos", visto en:http://sedll.org/es/admin/uploads/ congresos/15/act/115/nuevo_de_gloria-rosa.pdf Ernst Cassirer nos dice, "El lenguaje no entra en un mundo de percepciones objetivas sólo para asignar "nombres" que sería signos puramente exterior y arbitrarios a objetos individuales dados y claramente delimitados los unos respecto de los otros. Es de por si un mediador en la formación de objetos; es, en un sentido, el mediador por excelencia, el instrumento más importante y precioso para la conquista y la construcción de un verdadero mundo de objetos". Cassirer, Ernst, "El lenguaje y la construcción del mundo de los objetos", en, Psicología del lenguaje, Editorial Paidos, Buenos Aires, 1952, p. 25. "Wittgenstein planteará en Investigaciones filosóficas (1988) la imposibilidad de pensar el lenguaje indepen-dientemente de la visa social de la que forma parte. En este sentido, considerar que "imaginar un lenguaje significa imaginar una forma de vida -tal como el autor nos dice- es pensar en un entrelaza-miento tal entre lenguaje y práctica social que tiene como derivación en el planteo wittgensteiniano una concepción del lenguaje como práctica, -mejor dicho, como conjunto de practicas o actividadesY esto lo lleva a pensar el lenguaje en función de su uso ", Acevedo, Mariela Helilse, "Lenguaje y mundo social; la relevancia pragmática del lenguaje, en, Nomadas", Revista de ciencias sociales y juridicas, 30 (2001.2), Universidad Complutense de Madrid, visto en:http://pendientedemigracion. ucm.es/info/nomadas/30/marielaacevedo.pdf. No es la pretensión de este ensayo entrar a la discusión sobre la necesidad de leer a un autor en su lengua original para comprender mejor su planteamiento filosófico, esa discusión de por sí ya es compleja y da para una investigación, sin embargo, hemos tratado de fijar posición al respecto, para finalizar recordamos las palabras de Wittegenstein en su Tratactus lógico-philosophicus de 1922, "Die Grenzen meiner Sprache bedeuten 
habitual, sino todo lo contrario, Heidegger quiere conducirnos precisamente a lo inhabitual ${ }^{33}$. Ge-stell ${ }^{34}$ significa, en la lengua vernácula alemana, aquella armazón con diversas funcionalidades, ordenar, mostrar, ser soporte, de algo, por lo que, ser funcional, es algo de suyo, que busca poner orden, encajar, reunir diversos elementos. Ge-stell es siempre un lugar (Stelle) donde algo es puesto (gestellt), poner que busca la reunión de esos elementos en su «unidad significativa».

Ge-stell significa, en un primer momento, un compuesto, que compone, es por un lado producto, pero al mismo tiempo produce una configuración de unidad significativa del orden o racionalidad humana. El término Ge-stell implica una triple determinación: la determinación de la articulación de un conjunto, la determinación de un lugar, y por último, la determinación de una figura. En cuanto a la primera determinación, en la palabra Ge-stell aparece un primer elemento fundamental, el sentido de compuesto, es decir, de algo Ge-stell, resultado de una acción, la que a su vez resulta de con-juntar algo, de construir algo, de un Gefüge. El resultado de ese con-juntar, es un producto estructurado, que a su vez es estructurante, por lo que ese carácter de compuesto de Gestell, es, simultáneamente, una composición, génesis de un proceso indefinido de componer, su sentido más propio es entonces la articulación unificadora de lo diverso, de ahí, que la determinación estructural o lexicológica de un conjunto devenga para Heidegger en una determinación ontológica del destino de las cosas y del hombre en el Geshick des Seins.

"Aquello que determina la cohesión o unidad de un colectivo no es, en efecto, más que la ley de un acontecer conjunto e inseparable: la marca de lo que en otros textos Heidegger llamará el Er-Eignis, el radical acaecer en el que el ser y el hombre se apropian recíprocamente" ${ }^{35}$.

Con respecto a la segunda determinación, Stelle significa colocar, poner en un lugar (Stelle). En el lugar determinado por la Ge-stell es definido por la estructura y el fin por el cual ésta fue creada. "Todo Ge-stell es, pues, también un lugar donde algo es colocado, puesto, situado. Y, de la misma manera, él mismo es algo puesto y definido como lugar" ${ }^{36}$. De ahí que la técnica sea, en su sentido más originario, un lugar, o más bien un no-lugar, donde el ser se muestra, por ello, la técnica es también una forma de á̉ńசદıa.

die Grenzen meiner Welt", palabras que se han traducido como, "Los limites de mi lenguaje son los límites de mi mundo" y "Allí donde están las fronteras de mi lengua, están los limites de mi mundo".

33. Véase, Biemel, Walter, Heidegger, Rowohlt, Reimbeck bei Hamburg, 1973.

34. Para la explicación del uso del término Ge-stell partiremos del artículo de Borges Duarte, Irene, "La tesis heideggeriana acerca de la técnica", en, Anales del Seminario de Historia de la Filosofía, número 10, Editorial Complutense, Madrid, 1993, pp. 121-156. Por lo que, sino señalamos lo contrario, siempre nos estaremos moviendo en el análisis de la autora.

35. Borges Duarte, Irene, op. cit., p.133.

36. Ibidem. 
La última de las determinaciones de Ge-stell, la figura. Al ser Ge-stell un lugar de cohesión de un múltiple, ésta, implícitamente, guarda relación con Gestalt (figura); pero, ¿cómo debe comprenderse ese carácter de figura de Ge-stell? Éste debe comprenderse, nos dirá Heidegger, desde aquel poner y composición que, como tal, se instala en la obra ${ }^{37}$, la obra es así obra del ser, lo que significa que a través de ella, el ser viene a presencia. Lo mismo acontece en la técnica, la técnica es como un no-lugar donde el ser hace una especie de hueco para venir a presencia. De esta manera, Ge-stell es un dar-lugar al ser, por lo que es como una determinación ideológica de una «imagen mundo», y producción del ahí, es decir, de la aperturidad (Erschlossenheit) en la cual el ser se aclara y viene a presencia, el lugar creado de esta forma, que más que lugar, como se ha señalado anteriormente, es un no-lugar, se manifiesta como figura ${ }^{38}$.

\begin{abstract}
“Gestell, el armazón artificialmente construido por el hombre para servir de marco o de soporte a un sinfín de cosas posibles de un sinfín de situaciones, es el símbolo de este último «dar lugar dentro de lo que cabe» (dentro de lo calculado), en el que la organización y la fiscalización, informatización y la ideología - es decir, las estructuras artificiales- definen los contornos y encuadran todas las posibilidades del estar-en-el-mundo. Ge-stell es, entonces, el nombre de esa realidad-estandar, lugar del acontecer conjunto y unido del ser en la historia humana, extremada en la formula orweliana de «1984», que apenas ya es capaz de ser percibida" ${ }^{39}$.
\end{abstract}

A partir de lo expuesto hasta este punto es posible enfatizar por qué comenzamos este trabajo recurriendo a una aproximación a la estructura existencial de la cotidianidad (Alltäglichkeit) del Dasein. Queda claro además que el significado de Ge-stell dista del mero montaje, del hacer encajar los diversos instrumentos o dispositivos de algo técnico, si Ge-stell fuese eso, Heidegger estaría comprendiendo la esencia de la técnica desde la técnica misma, y no sería más que una descripción de lo que está incluido en el género de las cosas técnicas.

La esencia de la técnica “[...] consiste en la forma característica que la realidad gana en el mundo en el que se da la consumación nihilista de la historia de Occidente, es decir, en la figura-esbozo-proyección de una imagen del mundo ideológica, tecnológicamente trazada y programada" ${ }^{40}$.

Antes de continuar nuestro recorrido y aproximarnos a una de las vinculaciones esenciales que Ge-stell tiene con otros conceptos esenciales heideggerianos debemos señalar que la traducción al español de este término, Ge-stell, ha sido

37. Véase, Heidegger Martin, "El origen de la obra de arte, apéndice", en, http://www. heideggeriana.com.ar/

38. Cfr., Borges Duarte, Irene, op. cit., p. 139.

39. Ibidem.

40. Ibid., p. 146. 
diversa, caso similar es el del concepto de Ereignis

"De las versiones castellanas existentes, resalta el intento de asepsia, al seleccionar el sentido de Ge-stell como armazón o dispositivo, evocando la imagen de un mundo automatizado a lo Orwel o Huxley. Carpio, como antes el italiano Vattimo, lo hace por «imposición». H. Cortez y A. Leyte, como antes García-Bacca, lo hacen finalmente, con toda coherencia, por «composición» [...] En efecto, no sólo respeta la etimología, sino que, aunque se aleje del contenido concreto y vulgar de la voz alemana, no pierde, sin embargo, el impacto que Heidegger quiere guardar a Ge-stell. Este significa, en efecto, algo compuesto, que entra a su vez y deforma determinante en la composición de otros compuestos. Ambos sentidos, activo y pasivo, aparecen respetados en el castellano «composición»" 41 .

Ge-stell, estructura desde su ser-estructura. Félix Duque nos dice en este sentido que la traducción de Ge-stell como imposición es una mala traducción, la forma más adecuada de com-prender la esencia de la técnica es como «estructura»42. Hasta aquí hemos tratado de dar cuenta de aquello que sea Gestell, ahora pretendemos realizar una sucinta aproximación a las vinculaciones que la esencia de la técnica, Ge-stell, tiene con otros conceptos heideggerianos que a lo largo de lo hasta aquí expuesto han ido apareciendo ${ }^{43}$.

\section{a)das Ge-stell como desocultar-provocante (herausforderndes Entbergen)}

"La técnica es un modo del desocultar. La técnica presencia en el ámbito en el

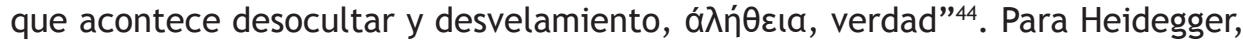
la esencia de la técnica, Ge-stell, es una forma de desocultación, sin embargo, la desocultación que comporta la técnica moderna dista mucho de la desocultación

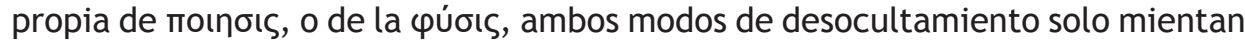
lo que aún no está ante nosotros, lo decisivo en estos modos de desocultamiento no es el hacer ni el manipular las cosas, en ellos, las cosas simplemente acontecen, ambos son modos abrientes, y las cosas vienen a presencia como parte de dicho movimiento. En la técnica acontece un modo bastante particular de verdad, no debemos olvidar que aquello que es desvelado es precisamente la verdad, la verdad del ser, este modo de verdad aconteciente en la técnica posee también un modo particular de desvelamiento o desocultación, a saber, el desocultarprovocante (herausforderndes Entbergen), por esta forma de desocultación el

\footnotetext{
41. Ibid., p. 148

42. Cfr., Duque, Felix, op. cit., p. 26.

43. Para mostrar estas vinculaciones seguiremos la investigación realizada por el Prof. y Dr. Jorge Acevedo Guerra, "Meditación acerca de nuestra época: una era técnica", en, Revista Observaciones Filosóficas, $\mathrm{N}^{\circ}$ 3, Chile, 2006 y que posteriormente fuera recogida en, Acevedo Guerra, Jorge, Heidegger: existir en la era técnica, Ediciones Universidad Diego Portales, Santiago de Chile, 2014. 44. Technik ist eine Weise des Entbergens. Die Technik west in dem Bereich , wo Entbergen und

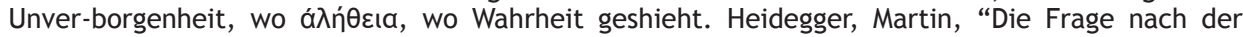
Technik", op. cit., 13.
} 
hombre se ve impulsado a descubrir o desocultar de una manera a priori lo que hay desde un horizonte de utilidad ${ }^{45}$, por esta forma de desocultación el hombre impone a la naturaleza la exigencia de liberar y suministrar su estructura interna para ser racionalizada y luego utilizada, almacenada y explotada ${ }^{46}$. La técnica moderna no permite que el proceso de desocultamiento acontezca por sí mismo, sino que lo acelera, lo modifica y desvía, lo racionaliza en función de fines e intereses humanos. La técnica moderna interpreta la naturaleza entera como un útil a la mano, "Por el contrario, una región es provocada a la extracción de carbón y minerales. La tierra se desoculta como región carbonífera, el suelo como lugar de yacimiento de minerales"47. El desocultamiento que acontece en la técnica es entonces, un provocar, un desafiar, y un emplazar. Esta forma de desocultamiento transforma al mundo y a la naturaleza en un "constante", punto que nos lleva al segundo vínculo esencial de la técnica.

\section{b) Das Ge-stell y los entes como constantes (Bestände)}

Al ser la técnica una manera de desocultar-provocante (herausforderndes Entbergen), la naturaleza ya no trae a presencia libremente aquello que está oculto, el desocultar de la téxvn era un traer-a-presencia, la técnica moderna, es un exigir-hacia-afuera, el objeto (Gegenstand) así, ha dejado de serlo en esta forma de desocultamiento. Y puesto que la técnica moderna es la liberación de lo oculto en la naturaleza desde un horizonte de utilidad, aquello que llega a presencia de esta forma no es más que un útil (Nüztlich) que responde a los intereses del hombre, intereses que buscan y que de hecho, lo han realizado, convertir a la naturaleza en un almacén de materias disponibles. El objeto (Gegenstand) entonces no es más un objeto, ahora los entes acontecen como «Constante» (Bestand), como objetos de consumo, como existencias constantes (Bestände).

"El modo de esta destinación es la objetividad (como ser-objeto del objeto). Ahora bien, mientras más se despliega la técnica moderna, más se transforma la objetividad, Gegenständlichkeit, en Beständlichkeit (mantenerse a disposición). Hoy ya no hay más objetos, Gegenstände (el ente en cuanto se mantiene enhiesto frente a un sujeto que lo tiene en vista) no hay más que Bestände (el ente que se mantiene listo para ser consumido); en francés quizás se podría decir: no hay más substancias sino únicamente subsistencias, en el sentido de "reservas". De donde las políticas de energía y de regimentación del territorio, que efectivamente no tienen ya relación con los objetos sino que, en

45. Cfr., Acevedo Guerra, Jorge, op.cit. p. 21.

46. Cfr., Linares, Jorge, “La concepción heideggeriana de la Técnica: Destino y peligro para el ser del hombre”, en, Signos filosóficos, número 10, julio-diciembre, Iztapalapa, 2003, pp. 15-44, para la cita, p. 31.

47. Ein Landstrich wird dagegen in die Förderung von kohle und Erzen herausgefordet. Das Erdreich entbirgt sich jetz als kohlenrevier, der Boden als Erzlagerstätte. Heidegger, Martin, “Die Frage nach der Technik", Op.cit., p. 14. 
el marco de una planificación general, ponen sistemáticamente en orden el espacio en vista de una explotación futura. Todo (el ente en su totalidad) toma lugar de golpe en el horizonte de la utilidad, del ordenamiento (commandement), o, mejor aún, del comandamiento (commanditement) de eso de lo que es necesario apoderarse. El bosque deja de ser un objeto (lo que era para el hombre científico de los siglos XVIII-XIX) y se convierte, para el hombre revelado finalmente como técnico, es decir el hombre que a priori se dirige al ente en el horizonte de la utilización, en "espacio verde". Nada más puede aparecer en la neutralidad objetiva de un cara a cara. Sólo hay Bestände, stocks, reservas, fondos" ${ }^{48}$.

\section{c) Das Ge-stell y la unicuadridad o cuaternidad (das Geviert)}

Para Heidegger la Ge-stell "es el acabamiento y cumplimiento de la metafísica" sin embargo, esta figura del ser, nos dice Heidegger, es al mismo tiempo aquello que posibilita el surgimiento y descubrimiento del Ereignis. Ahora se comprende mejor la afirmación heideggeriana que la Ge-stell es el negativo fotográfico del Ereignis. Y es desde éste, Ereignis, que el ser se dona y destina, "Das Schicken ist aus den Ereignen" señala Heidegger; pero, ¿de qué manera se dona el ser? El ser se dona desde lo abierto del Ereignis como reunión de lo cuadrante (Das Geviert): cielo, tierra, divinos y mortales ${ }^{49}$. La cuaternidad (Das Geviert) guarda una proximidad con el Ereignis, y es debido a esta proximidad y a lo abierto en la cuadratura -que por cierto, guarda estrecha relación con el habitar (whonen), tema fundamental en Heidegger- que la historia queda abierta ya que las figuras del ser serían inagotables, Heidegger nos dice, "Ser: Nada: Mismo" ${ }^{50}$.

“Ser: Nada: Mismo' significa que el futuro es radicalmente abierto e indeterminado, siendo, por tanto, inimaginable algo así como el fin de la historia. La estructura misma del ser impediría ha-cer un planteo como el que habría sostenido Fukuyama. Aunque ser sea cuestión disputada, su histo-ricidad -por tanto, su plasticidad y radical apertura al futuro-, es un punto de partida indiscutible para Heidegger, lo que le aleja de manera tajante de toda interpretación abstracta y evanescente del ser" ${ }^{51}$.

\section{d) Das Ge-stell y el Ereignis}

Ya se ha señalado la relación existente entre la Ge-stell y el Ereignis, ambos forman una unidad, unidad que no parte de la igualdad de ellos sino de su

48. Heidegger, Martin, Seminario Le Thor 1969, op. cit.

49. Cfr. Acevedo Guerra, Jorge, Heidegger: existir en la era técnica, Ediciones Universidad Diego Portales, Santiago de Chile 2014, p. 293.

50.Cfr. Heidegger, Martin, Protocolo a Seminario Le Thor 1969 , visto en-http: / /www. heideggeriana. com.ar/textos/le_thor.htm

51. Acevedo Guerra, Jorge, Heidegger: existir en la era técnica, Op.cit. p. 295 
diferencia, son idénticos porque son diferentes ${ }^{52}$. Del peligro que es la Ge-stell florece la salvación nos dirá Heidegger, es decir, el Ereignis, y es desde éste que el ser (Sein) se donará y destinará en una nueva forma de habitar en la cuaternidad (Das Geviert).

\section{Síntesis y conclusión}

El presente trabajo no ha tenido más pretensión que la de mostrar una serie de relaciones presentes en la reflexión heideggeriana sobre la técnica mostrando que ésta no es periférica sino que ocupa un lugar relevante en el despliegue de su pensamiento, muchas de estas relaciones son sumamente complejas y no es la pretensión de este pequeño ensayo profundizar en ellas, sino, como se dijo anteriormente, dejarlas señaladas. Tampoco se ha pretendido entrar a la discusión actual alrededor de la técnica, discusión importante, sino simplemente acercarnos a algunos elementos del pensamiento heideggeriano alrededor de ella. El tema de la cuaternidad (das Geviert) y el Ereignis son temas sumamente complejos en sí mismos, y son fundantes, sin ser fundamentos, del otro pensar (Das Andere Denken) por lo que este no es el lugar para realizar un análisis de dichos términos, sin embargo, su relación con la técnica es fundamental, de allí que fuese nuestro interés señalarla.

La pregunta heideggeriana sobre la esencia de la técnica apunta a una instancia, Das Ge-stell, que está fuera del arbitrio del ser humano, instancia que ha emergido, sin embargo, producto de la acción de éste. Esta instancia implica además una destinación del ser, lo que significa, y he aquí la razón del por qué no está bajo el arbitrio del ser humano, que posee su dinámica propia con una dimensión histórica particular que forma parte de la historia de la humanidad. Das Ge-stell como se ha visto en el despliegue de este trabajo es una forma de desvelación o desocultación, a la que Hiedegger llama, desocultar-provocante (herausforderndes Entbergen), es decir, hay un tipo histórico de verdad en esta figura del ser. La técnica moderna al ser un desocultar-provocante (herausforderndes Entbergen) obliga a la naturaleza a la liberación de energía bajo la pretensión de su acumulación, y es aquí, en este afán de acumulación donde inclusive los objetos (Gegenstände) que en su momento diluyeron a la cosa (Das Ding) -comprendiéndola en términos Hiedeggerianos ${ }^{53}$ - se ven trastocados por esta figura del ser y su forma de desocultamiento pasando a ser lo constante (Bestände), por ello es que estos objetos (Gegenstände), ahora acumulados, son vistos en termino de existencia (Bestände) $)^{54}$. Los entes en la era técnica son existencia (Bestände), reservas, inventario, inclusive, la tierra no es más que un campo de producción o de extracción de materias primas por lo que el habitar

52. Veáse, Heidegger, Martin, Identidad y Diferencia, edición bilingüe, edición de Arturo Leyte, traducción de Helena Cortéz y Arturo Leyte, ANTHROPOS, Barcelona, 1990.

53. Veáse, Heidegger, Martín, "La cosa”, en, Filosofía, ciencia y técnica, Prólogo de Francisco Soler y Jorge Acevedo, Editorial Universitaria, Santiago de Chile, 2007, pp. 233-261.

54. Cfr. Heidegger, Martin, Seminario de Le Thor 1969, en:http://www.heideggeriana.com.ar/ textos/le_thor.htm 
(Wohnen) ha caído en la indigencia y el ser humano ha perdido su morada, el ser humano mismo es visto ahora como material humano (Menschenmaterial), mano de obra. Dicho lo anterior es pertinente afirmar que la crítica heideggeriana penetra hasta los cimientos mismos sobre los cuales yace nuestro humanismo moderno señalando las ambigüedades presentes en éste, su pensamiento así ha constituido un desenmascaramiento de la supuesta neutralidad que la ciencia y la técnica poseen, mostrando además el carácter violento que impera es nuestras construcciones culturales actuales determinadas por el pensamiento técnico, es decir, el pensamiento calculador (das Rechnende Denken) ${ }^{55}$.

Pero, ante este pensamiento calculador (das Rechnende Denken), Heidegger señala la importancia del pensamiento meditativo, el cual no acumula, sino que silencia y vacía. La reflexión que surge de este pensar meditativo (das Besinnliche Nachdenken) es para Heidegger el pensar por excelencia. Heidegger no pretende la imposición de un pensar meditativo (das Besinnliche Nachdenken), sino una relación de ambas formas de pensar, porque ambas son importantes, sin embargo, señala Heidegger, es el pensar meditativo (das Besinnliche Nachdenken), quien debe dirigir, en cierto sentido, al pensamiento calculador (das Rechnende Denken).

Este pensar meditativo (das Besinnliche Nachdenken) requiere, dice Heidegger, que el ser humano se comprometa a algo, a habitar una actitud libre frente a la técnica, habitar el querer y no-querer que rompería la dependencia que el hombre actual ha establecido con el mundo técnico, a esta actitud Heidegger llama, Gelassenheit o desasimiento, sólo es este desasimiento el que nos permite tener una actitud libre ante la imposición que la técnica implica ${ }^{56}$.

“La esencia de la técnica sólo surge a la luz del día lentamente. Ese día es la noche del mundo transformada en mero día técnico. Ese día es el día más corto. Con él nos amenaza un único invierno infinito. Ahora, no sólo se le niega protección al hombre, sino que lo salvo de todo lo ente permanece en tinieblas. Lo salvo se sustrae. El mundo se torna sin salvación, pierde todo carácter sagrado. De este modo, no sólo lo sagrado permanece oculto como rastro que lleva hacia la divinidad, sino que hasta esa huella hacia lo sagrado, lo salvo, parece haber sido borrada. A no ser que haya todavía algunos mortales que sean capaces de ver cómo les amenaza la falta de salvación en tanto que falta de salvación. Tendrían que llegar a ver qué peligro acecha al hombre. El peligro consiste en esa amenaza que atañe a la esencia del hombre en su relación con el propio ser y no en peligros casuales. Este peligro es el peligro. Se esconde de todo ente en el abismo. A fin de que el peligro

55. Cfr., Cavallé, Mónica, La sabiduría de la no-dualidad, una reflexión comparada entre Nisargadatta y Heidegger, Editorial Kairós, Barcelona, 2008, pp. 240-243.

56. Cfr., Heidegger, Martin, Serenidad, Traductor Yves Zimmermann, ODÓs, Barcelona, 1989, p. 36 
sea visto y mostrado, tiene que haber esos mortales que son capaces de alcanzar antes el abismo" ${ }^{57}$.

\section{Bibliografía}

\section{a) Textos fuente}

Heidegger, Martin, Filosofía, ciencia y técnica, Prólogo de Francisco Soler y Jorge Acevedo, Editorial Universitaria, Santiago de Chile, 2007.

Heidegger, Martin, Vorträge und Aufsätze, Vittorio Klosterman, Frankfurt am main, 2000. Heidegger, Martin, Ser y tiempo, Traducción, prologo y notas por Jorge Eduardo Rivera, Ed. Trotta, Madrid, 2003.

Heidegger, Martin, Sein und Zeit, Max Niemeyer Verlag, Tübingen.

Heidegger, Martin, Serenidad, Traducción, Yves Zimmerman, ODÓS, Barcelona, 1989.

Heidegger, Martin, Meditación, Traducción Dina V. Picotti C. Editorial Biblos, Buenos Aires, 2006.

Heidegger, Martin, Identidad y Diferencia, Edición bilingüe, Edición de Arturo Leyte, traducción de Helena Cortés y Arturo Leyte, Anthropos, Barcelona, 1990.

Heidegger, Martin, Beiträge zur Philosophie (Vom Ereignis), Vittorio Klosterman, Frankfurt am main, 2003.

Heidegger, Martin, Contribuciones a la Filosofía (Del acontecimiento), Traducción de Breno Onetto Muñoz, Traducción presentada como proyecto de investigación postdoctoral, 1999-2002, Chile.

\section{b) Textos complementarios}

Cavallé Mónica, La sabiduría de la no-dualidad, una reflexión comparada entre Nisargadatta y Heidegger, Editorial Kairós, Barcelona, 2008.

Biemel, Walter, Heidegger, Rowohlt, Reimbeck bei Hamburg, 1973.

Cohn, Priscilla, Heidegger, su filosofía a través de la nada, Ediciones Guadarrama, Madrid,1975.

Acevedo Guerra, Jorge, Heidegger: existir en la era técnica, Ediciones Universiad Diego Portales, Santiago de Chile, 2014.

Basso Monteverde, Mercedes Leticia, Génesis y constitución del Ereignis. Un estudio de la continuidad de la obra de Martin Heidegger [1919-1939] a través del problema de la diferencia ontológica, Tesis para optar al grado de Doctora en Filosofía, UBA, Argentina, 2013.

\section{c) Revistas}

Duque, Felix, "En los confines de la Metafisica", en Anales del Seminario de Historia de la Filosofía, número 13, 19-38, Servicios de publicaciones UCM, Madrid, 1996.

Borges Duarte, Irene, "La tesis heideggeriana acerca de la técnica”, en, Anales del Seminario de Historia de la Filosofía, número 10, 121-156, Editorial 
Complutense, Madrid, 1993.

Linares, Jorge, "La concepción heideggeriana de la Técnica: Destino y peligro para el ser del hombre”, en, Signos filosóficos, número 10, julio-diciembre, Iztapalapa, 2003, pp. 15-44.

Acevedo, Guerra, Jorge, "Meditación acerca de nuestra época: una era técnica”, en, Revista Observaciones filosóficas, número 3, Chile, 2006.

González, Antonio, “Ereignis y actualidad”, en, D. Gracia (ed.), Desde Zubiri, Ed. Comares, Granada, 2004, pp. 102-193.

\section{d) Linkografía}

Heidegger, Martin, “¿Y para qué poetas?”, traducción de Helena Cortés y Arturo Leyte, en, http://www.heideggeriana.com.ar/textos/rilke.htm

Heidegger, Martin, “Seminario Le Thor 1969”, Traducción de Diego Tatián, Alción editora, Cordoba, 1995. Visto en, http://www.heideggeriana.com.ar/textos/le_thor.htm

Del Barco, Óscar, "Sobre el concepto de Dios en Heidegger”, en Exceso y Donación. La Búsqueda del Dios sin Dios, Buenos Aires, Biblioteca internacional Martin Heidegger, 2003, pp. 97-112. Visto en, http://www.heideggeriana.com.ar/ textos/le_thor.htm

Hinostroza Gloria, "La construcción del mundo a través del lenguaje y la literatura" visto en: http://sedll.org/es/admin/uploads/congresos/15/act/115/nuevo_ de_gloria-rosa.pdf

Acevedo, Mariela Helilse, "Lenguaje y mundo social: la relevancia pragmática del lenguaje”, en, Nómadas, Revista de ciencias sociales y jurídicas, 30, Universidad complutense de Madrid, 2001, visto en: http://pendientedemigracion.ucm.es/ info/nomadas/30/marielaacevedo.pdf. 